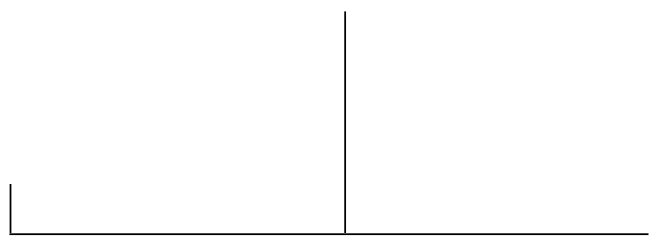

Rev. Latinoam. Psicopat. Fund., São Paulo, 16(2), 260-272, jun. 2013

\title{
Os tratamentos para usuários de drogas em instituições de saúde mental: perspectivas a partir da clínica psicanalítica*
}

Cynara Teixeira Ribeiro Andréa Hortélio Fernandes

O artigo analisa os tratamentos oferecidos aos usuários de drogas a partir da perspectiva psicanalítica. São explicitadas as especificidades da direção do tratamento na clínica das toxicomanias, enfocando os conceitos de sujeito, gozo e ética, elucidados através de fragmentos de casos clínicos. Conclui-se que a clínica psicanalítica contribui com estes tratamentos por possibilitar o reposicionamento subjetivo e outras formas de circunscrição de gozo.

Palavras-chave: Clínica, usuários de drogas, tratamento, psicanálise

*Artigo resultante da Tese de Doutorado intitulada $O$ tratamento para usuários de drogas em uma instituição de redução de danos: perspectivas a partir da psicanálise, defendida em 20/7/2012 no Programa de Pós-Graduação em Psicologia da Universidade Federal da Bahia - UFBA (Salvador, BA, Br.) sob a orientação da Profa. Dra. Andréa Hortélio Fernandes. 
Atualmente, em vários países do mundo, o uso de drogas é reconhecido como um grave problema de saúde pública. Em função deste reconhecimento, proliferam-se propostas de tratamento voltadas para usuários de psicoativos, as quais geralmente objetivam promover a abstenção ou a regulação do consumo.

A maioria destas propostas têm lugar em instituições de saúde mental e tendem a centrar-se nos efeitos neuroquímicos das substâncias psicoativas utilizadas, relegando, assim, a escuta clínica do sujeito. No entanto, há também instituições de atendimento a usuários de drogas orientadas pelo referencial psicanalítico. Nesse sentido, este artigo visa analisar as perspectivas fornecidas pela psicanálise no que tange à direção do tratamento na clínica das toxicomanias, utilizando-se, para tanto, de contribuições teóricas fornecidas por autores psicanalistas bem como de fragmentos de casos clínicos atendidos em uma instituição de saúde mental, conferindo destaque aos manejos realizados e aos seus efeitos analíticos.

\section{A atenção ao uso de drogas nas instituições de saúde mental}

Nos tratamentos oferecidos para usuários de drogas no âmbito das instituições de saúde mental, é possível situar a prevalência de dois modelos que, tradicionalmente, influenciam as propostas terapêuticas existentes neste campo: o modelo médico e o modelo moral (Faria \& Schneider, 2009). O primeiro concebe a toxicomania 
como uma forma de psicopatologia, com consequente ênfase nos aspectos orgânicos e biológicos associados a este fenômeno. Os tratamentos para uso de drogas provenientes deste modelo apresentam como características ser hospitalocêntrico, com predominância da terapêutica farmacológica e tendo como principal meta a cura, que, no caso da atenção aos usuários de álcool e outras drogas, é considerada equivalente à abstenção do uso.

Já o modelo moral é de origem religiosa ou espiritualista e propõe o uso de drogas como um desvio de caráter. Os tratamentos que se encontram inseridos nesta vertente visam moldar nos usuários o comportamento desejado pela instituição, que geralmente equivale ao comportamento abstinente. Este modelo é ainda hoje adotado por algumas comunidades terapêuticas e por grande parte dos grupos de ajuda mútua, como os Alcoólicos Anônimos e Narcóticos Anônimos, que propõem a dependência química como uma doença física, mental e espiritual incurável.

É comum observar que, nas instituições de saúde mental voltadas à atenção aos usuários de álcool e outras drogas, as práticas terapêuticas existentes geralmente fazem uma síntese destes dois modelos. Além disso, tais instituições inserem-se massivamente na lógica das instituições especializadas, nas quais um determinado usuário é atendido por vários especialistas, supostos detentores de um saber a priori sobre o uso de drogas, sem que haja um diálogo ou integração destes saberes a partir de cada caso singular. Nessa perspectiva, os tratamentos oferecidos costumam pautar-se em ideários científicos ou morais acerca das concepções de doença, cura, reabilitação etc.

Diferentemente, nos tratamentos oferecidos aos usuários de drogas a partir da perspectiva psicanalítica, a ênfase recai no sujeito que lança mão do recurso aos psicoativos, na dimensão do gozo atrelado às práticas de intoxicação e na ética que orienta a clínica psicanalítica, a qual se caracteriza por ser uma ética do bem-dizer e se opõe ao que Lacan ([1958/1959]/1995) chama de ética do bem-estar.

\section{A perspectiva psicanalítica nos tratamentos para usuários de drogas}

O estudo do fenômeno do uso de drogas e das suas diferentes modalidades de tratamento tem revelado cada vez mais a importância de levarmos em consideração o sujeito que recorre às substâncias psicoativas e o gozo atrelado às práticas de intoxicação (Torossian, 2004). A ideia de que, ao consumo de substâncias tóxicas, subjaz um sujeito que faz uma escolha e que consegue extrair desta prática um gozo, remete ao conceito de sujeito do inconsciente, o qual é concebido como estando além do indivíduo e da doença. 
Nesse sentido, uma das principais especificidades do tratamento analítico é sua ênfase na estrutura subjetiva em detrimento do fenômeno patológico individual. É por esta razão que, diferentemente do diagnóstico médico-psiquiátrico, que é fenomenológico e baseia-se em um conjunto de sinais previamente definidos, o diagnóstico psicanalítico é estrutural e visa analisar a posição assumida pelo sujeito diante do Outro (Figueiredo \& Tenório, 2002).

Uma das principais consequências da diferenciação entre fenômeno e estrutura no tratamento das toxicomanias diz respeito ao fato de que esta se contrapõe à perspectiva de tratamento das instituições especializadas (Martins, 2005). Tais instituições, como as especializadas em uso de drogas, distúrbios alimentares ou outras manifestações monossintomáticas, priorizam o fenômeno em detrimento da estrutura. Em função dessa lógica, estas instituições ratificam, nos seus usuários, uma identificação com os fenômenos que nelas são tratados, acarretando, assim, uma função de nomeação. Porém, um dos efeitos nefastos desta nomeação é que esta geralmente traz implícita a suposição de que um fenômeno é capaz de definir o sujeito, o que dificulta ou até impossibilita um questionamento, por parte do usuário, acerca daquilo que subjaz ao fenômeno.

Nesse sentido, na perspectiva da psicanálise, o diagnóstico busca o mais além dos fenômenos, preconizando uma clínica da escuta que objetiva analisar as maneiras como os efeitos de uma confrontação com o Outro se estabelecem na definição de uma estrutura do sujeito (Figueiredo \& Tenório, 2002). Dessa maneira, é a partir do diagnóstico diferencial entre neurose, psicose e perversão que o tratamento psicanalítico irá se desenrolar.

Isso porque a psicanálise propõe que o fenômeno do uso de drogas terá certas particularidades dependendo da estrutura na qual se manifesta. Assim, a perspectiva psicanalítica considera que as drogas podem ser usadas com diferentes funções e que o uso de drogas, enquanto fenômeno, apenas vela a estrutura subjetiva que o comporta. Portanto, no tratamento analítico oferecido aos usuários de drogas, torna-se necessário considerar a função e o sentido desse fenômeno para cada sujeito, o que apenas pode ser feito a partir de uma escuta clínica que produza efeitos subjetivos e que seja capaz de favorecer um reposicionamento do paciente ante as desordens de que se queixa.

Desse modo, a perspectiva psicanalítica, contrariamente ao modelo médico-psiquiátrico, o qual segue a lógica das instituições especializadas, prioriza o que Figueiredo (2007) denomina de saber do sujeito em detrimento do saber técnico. Enquanto no saber técnico o sujeito fica assujeitado a um saber que os técnicos de saúde julgam deter sobre o que acreditam ser a doença do paciente, a clínica psicanalítica parte de um não saber sobre o sujeito (Lacan, 1960/1961), apostando em um saber do sujeito, um saber "[...] suposto, oculto, não evidente, que se 
apresenta de modo difuso, intermitente, lacunar, e que precisa ser recolhido e trabalhado como indicador para o tratamento" (Figueiredo, 2007, p. 42).

Então, para que um tratamento psicanalítico das toxicomanias possa ter lugar em instituições de saúde mental especializadas no atendimento a usuários de drogas, é necessário que o praticante da psicanálise, que atua em tais instituições, consiga trilhar um percurso que vá do fenômeno à estrutura, tomando esta última como um guia que orienta a análise dos fenômenos e determina a direção a ser dada ao processo terapêutico. Em outras palavras, podemos afirmar que apenas é possível o estabelecimento de um tratamento analítico para as toxicomanias no espaço institucional na condição de haver uma subordinação dos dispositivos institucionais de tratamento à prática clínica. E essa condição é absolutamente necessária na atualidade, haja vista que a experiência tem demonstrado que o consultório privado é insuficiente como dispositivo para tratar a grande maioria dos chamados sintomas atuais.

\section{A direção do tratamento na clínica das toxicomanias}

No tocante à direção do tratamento analítico, Lacan (1998) afirma que quem dirige o tratamento é o analista, mas isso não significa dizer que o analista dirige o analisante. Para Lacan, dirigir o analisante seria correlato a dirigir a consciência, prática comum nos tratamentos morais, mas que deve estar excluída da experiência analítica. Nesse sentido, ele adverte que a direção do tratamento analítico consiste, em primeiro lugar, em fazer com que o sujeito aplique a regra analítica, falando o que lhe vier à cabeça, e abrindo-se, assim, aos efeitos do inconsciente. É por essa razão que a clínica psicanalítica das toxicomanias, diferentemente dos demais tratamentos voltados para usuários de drogas, se fia não em um saber prévio, mas nas escolhas do sujeito, na medida em que a direção do tratamento analítico é dada a partir da associação livre e, portanto, do inconsciente.

Assim, a psicanálise pauta-se em uma clínica da escuta, que, como tal, diferencia-se da clínica do olhar, característica do modelo psiquiátrico (Figueiredo \& Tenório, 2002). Porém, para que esta escuta possibilite o acesso ao saber inconsciente, é necessário que ela esteja ancorada no estabelecimento da transferência, pois é esta que, ao promover o deslizamento da cadeia significante, convida o sujeito do inconsciente a falar. Isso porque, sendo o pivô da transferência o sujeito suposto saber, que consiste no engano subjetivo do analisante em supor que há um saber, do lado do analista, acerca do seu infortúnio, é ele que faz com que o analisante demande ao analista uma resposta para suas questões. 
Nesse sentido, favorecer o advento do sujeito do inconsciente vai na contramão das propostas de tratamento para o uso de drogas que promovem uma identificação dos usuários com os significantes "toxicômano", "viciado", "doente" etc. Tais nomeações, ao trazerem implícita a suposição de que um fenômeno é capaz de definir o sujeito e ao tomarem o usuário de drogas como objeto de um saber que lhe é exterior, promovem o que a psicanálise chama de demissão subjetiva, na medida em que ratifica uma alienação dos usuários a significantes provenientes do Outro social, tamponando, assim, o sujeito do inconsciente. Diferentemente, a direção do tratamento psicanalítico visa possibilitar a implicação subjetiva, na medida em que convoca o sujeito a se responsabilizar pelo seu gozo, o qual, por mais que pareça alheio à sua vontade, lhe concerne e traduz a sua divisão subjetiva.

Mas, na clínica psicanalítica das toxicomanias, é importante considerar que o gozo em jogo nas práticas de intoxicação porta uma particularidade, na medida em que é capaz de fazer o sujeito romper com o gozo fálico, que é o gozo resultante da operação de castração (Lacan, 1976). É por esta razão que o gozo toxicômano articula-se ao que Lacan chamou de gozo perigoso. Pois, segundo Lacan, a dinâmica do gozo inclui a possibilidade de que o sujeito procure estender a satisfação sempre para mais além das coordenadas ditadas pelo princípio do prazer, visando, assim, uma excitação cada vez maior que, ao ser repetidamente levada ao seu limite extremo, pode chegar a tocar o ponto supremo do gozo, que é a morte. Nesse âmbito, o sujeito depara-se com um gozo perigoso, que ultrapassa a excitação mínima, pode chegar ao infinito e "[...] comporta a possibilidade de repetição que seria o retorno a esse mundo como semblante" (Lacan, 1970/1971, p. 20).

Esse gozo perigoso, tal como definido por Lacan, pode ser vislumbrado de maneira bem clara no fenômeno do uso de drogas e, em particular, nas chamadas toxicomanias, uma vez que a tentativa empreendida pelo toxicômano é a de lançar o gozo cada vez mais para o ponto limite da vida, aproximando-se gradativamente da morte na medida em que, a cada novo uso, aumenta a dose das substâncias utilizadas, pois a dose anterior já não é mais suficiente para fazê-lo sentir o mesmo efeito, o que pode culminar nas famosas "overdoses".

E de acordo com Alberti (2007), a única possibilidade de impor limites a esse gozo perigoso é reinseri-lo na regulação ditada pelo princípio do prazer, para que este possa fazer parte do gozo da vida e não configure uma extrapolação que culmine na morte do organismo. A partir dessa proposição, pode-se constatar que uma direção possível na clínica das toxicomanias é favorecer a reinserção do gozo perigoso oriundo das práticas de intoxicação em uma regulação fálica, aumentando, assim, o campo referente ao gozo da vida. 
Em perspectiva semelhante, Fernandes (2009) propõe que o manejo do mais-de-gozar na clínica psicanalítica deve seguir a orientação lacaniana de "[...] fazer o gozo passar pelo inconsciente" (Lacan, 2003, p. 107). Pois, segundo a autora, adotar essa direção no tratamento psicanalítico implica levar o sujeito a fazer um novo uso do gozo, responsabilizando-se por seus modos de gozar e, consequentemente, implicando-se naquilo de que se queixa.

Dessa forma, a clínica psicanalítica das toxicomanias, ao se pautar no diagnóstico estrutural e na interrogação acerca da função das drogas na economia psíquica de cada usuário, visa propiciar uma responsabilização do sujeito pelo seu gozo, não podendo estabelecer, a priori, nenhum ideal a ser alcançado. Assim, a abstinência de que se trata na clínica psicanalítica, especialmente no caso do tratamento das toxicomanias, é a abstinência do analista, o qual não deve aderir a um furor curandi que o levaria a querer aplacar, de antemão, o sofrimento do usuário.

Desse modo, na perspectiva da clínica psicanalítica, para que a toxicomania possa converter-se na formação de sintomas, é necessário que o tratamento oferecido permita que se produza um deslocamento deste objeto-solução, representado pela droga, para a confrontação com a falta radical de objeto. Este deslocamento é produto do confronto com o enigma do desejo do Outro, o qual possibilita a emergência do sujeito do desejo e, consequentemente, a delimitação de uma distância em relação ao gozo invasor vivenciado na experiência toxicômana.

Mas, a partir das referências de Lacan (1998), é possível depreender que esse deslocamento só tem possibilidades de acontecer caso a direção do tratamento tenha como operador o desejo do analista, o qual consiste em um desejo opaco que comparece como enigma e que, ao retornar para o analisante sob a forma da pergunta Che Vuoi?, é capaz de colocar em funcionamento o deslizamento dos significantes. Assim, o desejo do analista permite ao praticante da psicanálise fazer operar o Discurso do Analista, fazendo semblante de agente (a) deste discurso, $\mathrm{e}$, consequentemente, permitindo que o analisante possa aparecer como sujeito dividido (\$), com vistas à promoção de uma retificação subjetiva.

Segundo Bittencourt (1993, p. 13), no âmbito da clínica com toxicômanos, a retificação subjetiva consiste justamente na passagem do queixar-se da substância tóxica para o queixar-se de si mesmo. E essa passagem "[...] se dá quando a droga se transforma numa questão para ele: 'por que me drogo?'”. É neste momento que se pode testemunhar a vacilação do gozo proporcionado pela substância e o deslocamento necessário da droga para a sua dimensão significante. Em linhas gerais, pode-se dizer que esta é a direção do tratamento analítico na clínica das toxicomanias no tocante à estrutura neurótica. 
Por sua vez, quando se trata de um sujeito psicótico que usa drogas, a direção do tratamento analítico não pode visar a produção de um sintoma analítico e a divisão subjetiva, visto que a estrutura psicótica não conta com recursos para se haver com isso. Segundo Monteiro (2005), na clínica da psicose, a retificação subjetiva é substituída por uma introdução subjetiva, pois, como a condição do sujeito na psicose está sempre ameaçada, introduzir o sujeito é implicá-lo de alguma maneira no tratamento. Além disso, como na psicose o uso de drogas pode cumprir uma função que diz respeito a uma tentativa de silenciar os efeitos de foraclusão da Lei simbólica representada pelo Nome-do-Pai, o tratamento deve visar a um apaziguamento da invasão experimentada pelo sujeito, produzindo um anteparo ante o gozo intrusivo e ameaçador. Outra especificidade da clínica psicanalítica das toxicomanias com psicóticos diz respeito ao fato de que toda intervenção deve estar atenta para não dissolver a função por vezes apaziguadora que as drogas desempenham antes que algo possa se articular no lugar, sob o risco de desencadear uma passagem ao ato.

Dessa forma, a partir da clínica psicanalítica das toxicomanias, podemos pensar que a escolha do sujeito pelas drogas, as recaídas e os excessos de substância só poderão deixar de ser uma saída para os usuários de drogas quando o tratamento propiciar o encontro de cada um com outras formas de simbolização que o permitam prescindir da intoxicação, nos casos em que esse desfecho for possível.

\section{Fragmentos clínicos}

A fim de analisar como os pressupostos acima descritos podem comparecer na clínica psicanalítica das toxicomanias, lançaremos mão de dois fragmentos de casos clínicos: o caso de Maria e o caso de Leandro. A respeito do caso Maria, trata-se de uma mulher de quarenta anos que chegou ao tratamento com uma hipótese diagnóstica de psicose e apresentando-se como alguém que nasceu para sofrer, pois relatava já ter sofrido vários abusos sexuais, tanto do pai como dos irmãos e de alguns companheiros com quem conviveu maritalmente. Além disso, Maria se dizia perseguida e rejeitada. Afirmando que já estava cansada dos tantos abusos que havia sofrido, ela relatou que mandou matar um ex-companheiro como uma forma de se vingar de todos que a abusaram. Maria afirma ser um monstro e demanda que a responsável por seus atendimentos a veja como tal, chegando até mesmo a dizer-lhe que ela não se engane, pois não a conhece. Maria, inclusive, já fez várias atuações no intuito de provar sua monstruosidade, sendo, em função disso, temida por vários outros profissionais que a acompanham na instituição de saúde onde se trata. 
Porém, ao mesmo tempo em que demanda ser vista como um monstro, Maria também oferece à praticante da psicanálise que a atende sua abstinência de drogas, a qual apresenta como uma espécie de presente. Enquanto nos períodos de uso de drogas Maria apresenta-se de forma violenta e com trejeitos masculinizados, chegando a manter relações homossexuais; nos períodos de abstinência ela apresenta-se como benfeitora e com uma postura mais feminilizada.

No entanto, a praticante da psicanálise não responde do lugar em que é colocada por Maria: não teme o 'monstro' que Maria diz ser nem se ensoberbece com o suposto 'presente' que lhe é ofertado. Assim, por trabalhar com a hipótese de uma estrutura histérica e não dirigir-se a Maria como monstro, a psicanalista opera o que podemos chamar de um ato analítico, o qual, é importante salientar, não pode ocorrer fora da transferência. Esse ato, ao promover uma quebra na cadeia de significações estabelecida por Maria, suspende toda a ordem prévia e favorece a irrupção do novo. Assim, ao olhar para Maria sem vê-la como monstro, a analista possibilitou a emergência de um reposicionamento subjetivo ante o gozo oriundo da intoxicação. A partir daí, pode-se deduzir que, se o uso de drogas comparecia na vida psíquica de Maria como algo que lhe possibilitava tornar-se um 'monstro' (traficando, matando etc.), a posição da psiquiatra em não tomá-la deste lugar teve implicações sobre o modo de Maria se relacionar com as substâncias psicoativas bem como sobre seu posicionamento diante da partilha dos sexos. E esta direção que está sendo dada ao tratamento de Maria vem possibilitando que ela experimente circular por outras posições subjetivas que não a de monstro.

Por sua vez, no que tange ao caso Leandro, trata-se de um rapaz de trinta anos, que procurou uma instituição de tratamento para usuários de drogas a fim de interromper o consumo e satisfazer, assim, a vontade da mãe, que o acompanhava aos atendimentos. Leandro não trabalhava nem estudava e relatava ficar durante a maior parte dos dias em casa, atualizando um blog que havia criado e no qual escrevia textos e artigos sobre experiências com drogas.

Após algumas sessões, Leandro revelou que, nesse blog, nunca escrevia sobre suas próprias experiências com drogas, mas apenas sobre as experiências com drogas que ele observava em outros. Através de uma história na qual se observava uma linha muito tênue entre delírio e realidade, Leandro narrou que correria o risco de acontecer algo de muito ruim caso ele escrevesse no blog suas próprias experiências com as drogas e que tinha medo de sair na rua porque as pessoas estavam tramando contra ele. Inicialmente, Leandro justificou esse medo pela afirmação de que havia afrontado um pastor e que, por isso, o pastor queria se vingar dele, matando-o.

Porém, ao longo dos atendimentos e com a utilização de uma dosagem pequena de medicações antipsicóticas, Leandro começou a sistematizar seu delírio, o qual se caracterizava por ser um delírio de perseguição que inicialmente era 
direcionado apenas ao pastor e que, posteriormente, passou a ser dirigido a todas as pessoas da sua rua. Nesse caso, a direção do tratamento analítico seguiu a orientação segundo a qual, na clínica com psicóticos, o analista deve desempenhar a função de secretário do alienado, de modo a propiciar a construção delirante como uma tentativa de suplência à foraclusão da castração. Este manejo possibilitou certa regulação no consumo de drogas de Leandro na medida em que, ao longo do tratamento, ele encontrou uma abertura para, minimamente, simbolizar o gozo invasor característico da sua estrutura psicótica.

Dessa maneira, levando em consideração que o discurso analítico aproximase da lógica da operação de separação, ao promover uma ruptura, ainda que parcial, com a alienação do sujeito aos significantes fixados a partir do Outro, pode-se pensar que, no caso da clínica psicanalítica das toxicomanias, visa-se operar algo de uma separação não do Outro, mas do gozo perigoso do Outro que invade e escraviza o sujeito. Nessa perspectiva, segundo Lacan (1964/1998), se separar significa engendrar-se no âmbito dos tratamentos ofertados para os usuários de drogas e toxicômanos a partir da proposta da psicanálise, tratar-se-ia de fazer engendrar um sujeito onde apenas havia um corpo comandado pela substância tóxica ou pelo peso do significante fixado no objeto droga. A esse respeito, consideramos que as praticantes da psicanálise responsáveis pelos casos clínicos analisados conseguiram sustentar esta postura ética.

\section{Referências}

Alberti, S. (2007 abril). O bem que se extrai do gozo. Stylus: Revista de Psicanálise, Rio de Janeiro, 14, 65-76.

Bittencourt, L. (1993 maio). A clínica das entrevistas preliminares nas toxicomanias: a desmontagem da demanda de tratamento. Cadernos do NEPAD, Rio de Janeiro, l(1), 12-18.

Faria, J. G. \& Schneider, D. R. (2009 setembro/dezembro). O perfil dos usuários do CAPS ad-Blumenau e as políticas públicas em saúde mental. Psicologia e Sociedade, Florianópolis, 3(21), 324-333.

Fernandes, A. (2009). a mais de gozar. In A. Almeida (Org.). Objeto a: invenção lacaniana (pp. 59-65). Salvador: Associação Científica do Campo Psicanalítico.

Figueiredo, A. C. \& Tenório, F. (2002 março). O diagnóstico em psiquiatria e psicanálise. Revista Latinoamericana de Psicopatologia Fundamental, São Paulo, 5(1), 29-43.

Figueiredo, A. C. (2007). A clínica da Atenção Psicossocial: uma proposta da psicanálise. In J. T. Reis Filho \& V. C. Franco (Orgs.). Aprendizes da clínica: novos fazeres psi (pp. 37-47). São Paulo: Casa do Psicólogo. 
Lacan, J. (1976). Journées des cartels de l'École Freudienne de Paris. Lettres de l'École Freudienne, 18, 263-270.

Lacan, J. (1995). O seminário. Livro VII. A ética da psicanálise. Rio de Janeiro: Jorge Zahar. (Trabalho original publicado em 1958-1959).

Lacan, J. (1998). O seminário. Livro VIII. Transferência. Rio de Janeiro: Jorge Zahar, 1998. (Trabalho original publicado em 1960-1961).

Lacan, J. (1998). A direção do tratamento e os princípios do seu poder. In Escritos. Rio de Janeiro: Jorge Zahar.

Lacan, J. (2003d). Radiofonia. In Outros Escritos. Rio de Janeiro: Jorge Zahar.

Lacan, J. (2009). O seminário. Livro XVIII. De um discurso que não fosse do semblante. Rio de Janeiro: Jorge Zahar. (Trabalho original publicado em 1970-1971).

Martins, V. T. (2005). Que instituição para tratar de psicóticos que usam drogas? In S. Altoé \& M. M. de Lima (Orgs.). Psicanálise, clínica e instituição (pp. 136-144). Rio de Janeiro: Rios Ambiciosos.

Monteiro, C.( 2005). A clínica das psicoses e a prática psicanalítica nas instituições públicas de saúde mental. 124 p. Dissertação (mestrado em Psicologia Clínica). Universidade Católica de Pernambuco.

Torossian, S. (2004). De qual cura falamos? Relendo conceitos. Revista da Associação Psicanalítica de Porto Alegre, Porto Alegre, 26, 7-15.

\section{Resumos}

(Treatments for drug users in mental health institutions: perspectivesbased on the psychoanalytic clinic)

This paper presents an analysis of treatments provided to drug users from a psychoanalytic perspective. Specific aspects of the clinical direction of the treatment of addictions are discussed, with a special focus on the concepts of subject, jouissance and ethics, brought up through fragments of clinical cases. We conclude that the psychoanalytic clinic does contribute to such treatments by opening up possibilities for a repositioning of the subject and new ways to configure jouissance.

Keywords: Clinical, drug users, treatment, psychoanalysis

(Les traitements pour usagers de drogues dans les établisssemnets de santé mentale sous l'angle de la clinique psychanalytique)

Cet article analyse les traitements offerts aux toxicomanes $d u$ point de vue de la psychanalyse. Les spécificités de la direction du traitement de la clinique de la toxicomanie sont envisagées sous l'angle des concepts de sujet, de la jouissance et de l'éthique et illustrées à l'aide de fragments de cas cliniques. Nous concluons que la 


\section{SAÚDE MENTAL}

clinique psychanalytique contribue à ces traitements en permettent le repositionnement subjectif et d'autres formes de circonscription de jouissance.

Mots clés: Clinique, toxicomanes, traitement, psychanalyse

(Perspectivas de la clinica psicoanalítica: los tratamientos para los usuarios de drogas en las instituciones de salud mental:)

El artículo analiza los tratamientos que se ofrecen a los consumidores de drogas desde la perspectiva psicoanalítica. Se especifica la dirección clínica del tratamiento de adicciones, enfocando los conceptos de sujeto, gozo y ética, demostrados a través de fragmentos de casos clínicos. Se concluye que la clínica psicoanalítica ayuda en estos tratamientos al permitir formas de reposicionamiento subjetivo y otras formas de gozo.

Palavras claves: Clínica, usuarios de drogas, tratamiento, psicoanálisis

(Behandlungen von Drogenabhängigen in Einrichtungen für geistig Behinderte:

Perspektiven ausgehend von der psychoanalytischen Klinik)

In diesem Beitrag werden die Behandlungen, die den Drogensüchtigen angeboten werden, aus der psychoanalytischen Perspektive untersucht. Es werden spezifische Aspekte der Behandlungsansätze der Drogenabhängigkeit dargelegt, mit Schwerpunkt auf die Konzepte des Subjektes, der Lust und der Ethik, welche durch Fragmente der klinischen Fälle erläutert werden. Daraus wird geschlossen, dass die psychoanalytische Klinik zu diesen Behandlungen beiträgt, da sie die subjektive Neupositionierung und andere Formen von Umschreibung der Lust ermöglichen.

Schlüsselwörter: Klinik, Drogenabhängige, Behandlung, Psychoanalyse

Citação/Citation: Ribeiro, C. T. \& Fernandes, A. H. (2013, junho). Os tratamentos para usuários de drogas em instituições de saúde mental: perspectivas a partir da clínica psicanalítica. Revista Latinoamericana de Psicopatologia Fundamental, 16(2), 260-272.

Editor do artigo/Editor: Profa. Dra. Ana Cristina Costa de Figueiredo 
Recebido/Received: 2.11.2012/ 11.2.2012 Aceito/Accepted: 7.11.2012 / 11.7.2012

Copyright: (C) 2009 Associação Universitária de Pesquisa em Psicopatologia Fundamental/ University Association for Research in Fundamental Psychopathology. Este é um artigo de livre acesso, que permite uso irrestrito, distribuição e reprodução em qualquer meio, desde que o autor e a fonte sejam citados / This is an open-access article, which permits unrestricted use, distribution, and reproduction in any medium, provided the original author and source are credited.

Financiamento/Funding: As autoras declaram não terem sido financiadas ou apoiadas / The authors have no support or funding to report.

Conflito de interesses/Conflict of interest: As autoras declaram que não há conflito de interesses / The authors declare that has no conflict of interest.

\section{Cynara Teixeira Ribeiro}

Doutora em Psicologia pela Universidade Federal da Bahia - UFBA (Salvador, BA, Br.); Professora Adjunta da Universidade Federal do Semiárido - UFERSA (Angicos, RN, Br.).

Rua Raimundo Chaves, 1652, 2QB, Candelária

59064-390 Natal, RN, Br.

e-mail: cynara_ribeiro@yahoo.com.br

\section{Andréa Hortélio Fernandes}

Doutora em Psicopatologia Fundamental e Psicanálise pela Universitè de Paris VI; Professora Adjunta da Universidade Federal da Bahia - UFBA (Salvador, BA, Br.).

Estrada de São Lázaro, 197 - Federação

40210-730 Salvador, BA, Br.

e-mail: ahfernandes03@gmail.com 